\title{
Treating epilepsy with options other than antiepileptic medications
}

Osama Y. Muthaffar, SBPN, ABCN.

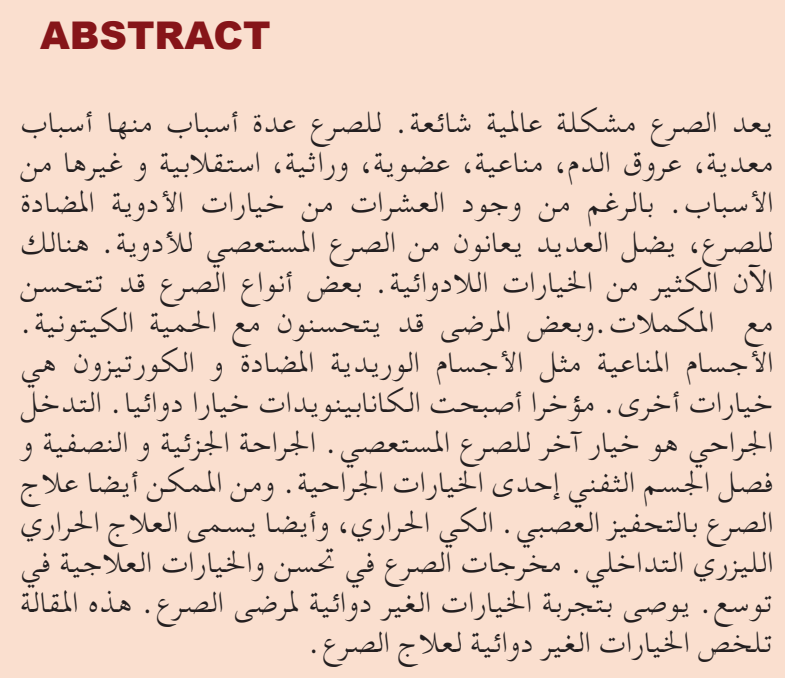

Epilepsy is a common health burden worldwide. Epilepsy is linked to variety of factors, including infectious, vascular, immune, structural, genetic, and metabolic etiologies. Despite the existence of multiple antiepileptic drugs (AEDs), many patients are diagnosed with intractable epilepsy. Many nonpharmacological options are available for epilepsy. Some types of epilepsy respond to cofactors. Other patients may be candidates for a ketogenic diet. Inflammatory mediators, such as intravenous immunoglobulins (IVIgs) and steroids, are other options for epilepsy. Recently, cannabinoids have been approved for epilepsy treatment. Refractory epilepsy can be treated with surgical interventions. Focal resections, hemispherectomies, and corpus callosotomies are some common epilepsy surgery approaches. Neuromodulation techniques are another option. Thermal ablation is a minimally invasive approach for epilepsy treatment. Epilepsy outcomes are improving, and treatment modalities are expanding. Trials of nonpharmacological options for epilepsy patients are recommended. This article summarizes available nonpharmacological options other than AEDs for the treatment of epilepsy.

Neurosciences 2020; Vol. 25 (4): 253-261 doi: 10.17712/nsj.2020.4.20200010
Department of Pediatrics, King Abdulaziz University, Jeddah, Kingdom of Saudi Arabia.

Received 27th January 2020. Accepted 4th May 2020

Address correspondence and reprint request to: Dr. Osama Y. Muthaffar, Department of Pediatrics, King Abdulaziz University, Jeddah,

Kingdom of Saudi Arabia. E-mail: oymuthaffar@kau.edu.sa

ORCID ID: https://orcid.org/0000-0002-3458-1697

$\mathrm{E}$ pilepsy is a common neurological condition in adults and children. ${ }^{1}$ It affects more than $1 \%$ of the population worldwide. ${ }^{2,3}$ In Saudi Arabia, its prevalence is $6.54 / 1000$ population. Epilepsy is a chronic disorder, and at least $10-40 \%$ of patients are diagnosed with intractable epilepsy. ${ }^{4}$ Charles Locock was the first to describe antiepileptic drugs (AEDs) in 1857 in the Lancet. He described the use of potassium bromide in what so called "hysterical epilepsy". ${ }^{3}$ In 1912, Alfred Hauptmann discovered phenobarbital. ${ }^{3}$ Phenytoin was introduced in 1938, followed later by first-generation AEDs (primidone, carbamazepine, ethosuximide and valproic acid). These first-generation AEDs were followed by second- and third-generation AEDs. However, about one- third of epilepsy patients are pharmacoresistant. ${ }^{4}$

In patients with intractable epilepsy (i.e., nonresponders to at least two appropriate AEDs), there are a number of available treatment options, which range from treatment with AEDs to nonpharmacological approaches. This review article focuses on available treatment options other than AEDs for epilepsy patients. There are few published reviews regarding this topic. This article provides a concise and updated review for the available nonpharmacological modalities.

Vitamin-responsive epilepsy and metabolic epilepsy. Epilepsy patients, especially neonates, may present with antenatal and neonatal seizures, including myoclonic seizures, infantile spasms, and tonic spasms. Motor regression, hypotonia, and movement disorders may also be part of the clinical picture of vitaminresponsive epilepsy among children of different 
ages. Pyridoxine (B6)-dependent epilepsy (PDE), pyridoxal 5'-phosphate-dependent epilepsy, folinic acid-responsive seizures, cerebral folate deficiency, biotinidase deficiency, biotin-thiamine-responsive basal ganglia disease, creatine disorders, glucose transporter type 1 (GLUT-1) deficiency, mitochondrial disorders, urea cycle disorders, glutaric aciduria, molybdenum cofactor deficiency, isolated sulfite oxidase deficiency, and tetrahydrobiopetrine deficiency are examples of metabolic and vitamin-responsive epilepsies. ${ }^{5,6}$

Pyridoxine (B6)-dependent epilepsy (PDE) can present early or later in life. Inheritance of PDE is mainly autosomal recessive manner. $A L D H 7 A 1$ are the comments pathogenic mutations causing PDE.

The neonatal presentation of PDE typically involves early neonatal seizures that are resistant to conventional AEDs. Once intravenous pyridoxine is administered, clinical and electrographic improvements are usually observed. Pyridoxine is recommended for all neonates with intractable seizures, especially before the age of 18 months. Older age presentation of PDE is also reported in the literature as intractable epilepsy and developmental delay. This presentation may be partially responsive to long-term treatment with $\mathrm{B} 6$. The presence of elevated $\alpha$-amino adipic semialdehyde in urine and plasma supports a diagnosis of PDE. The treatment dose of B6 is usually $15-30 \mathrm{mg} / \mathrm{kg} / \mathrm{d}$ BID (maximum daily dose $500 \mathrm{mg} / \mathrm{d}$ ) (Table 1). ${ }^{7,8}$

Epilepsy due to pyridoxal 5'-phosphate-dependent seizures is similar to that of PDE and should be suspected in neonates in whom seizures are intractable to conventional AEDs. Etiology of pyridoxal 5'-phosphatedependent epilepsy is a mutation in pyridoxamine 5'phosphate oxidase. Pattern of inheritance of pyridoxal 5'-phosphate-dependent epilepsy is mainly autosomal recessive manner. Infants with pyridoxal 5'-phosphatedependent epilepsy respond initially to B6, whereas others respond only to pyridoxal 5'-phosphate. Early initiation of pyridoxal 5'-phosphate (PLP) can result in seizure control. Recommended dosage of PLP is (30-50 $\mathrm{mg} / \mathrm{kg}$ TID). ${ }^{?}$

Folinic acid-responsive seizures and PDE share biochemical and genetic characteristics. Elevated CSF $\alpha$-amino adipic semialdehyde and CSF pipecolic acid have been reported in both conditions, as well as similar $A L D H 7 A 1$ gene mutations. Neonates with

Disclosure. Authors have no conflict of interests, and the work was not supported or funded by any drug company. folinic acid-responsive seizures may present with epileptic encephalopathy or later-onset seizures. A trial of pyridoxine and folinic acid should be considered in such cases. Dosage of $(3-5 \mathrm{mg} / \mathrm{kg} / \mathrm{d})$ is recommended. ${ }^{10}$

Cerebral folate deficiency usually presents with severe developmental delay, intractable epilepsy, movement disorders, and nonspecific white matter changes. It is mainly inherited in an autosomal recessive pattern. A CSF analysis shows low levels the active folate metabolite "5-methyltetrahydrofolate". A homozygous mutation in the FOLR1 gene has been reported. ${ }^{11}$ Similar to folinic acid-responsive seizures, cerebral folate deficiency patients can be treated with pyridoxine and folinic acid. This combination can result in cognitive and seizures improvement. ${ }^{11}$ Biotinidase deficiency is another form of cofactor-responsive epilepsy that presents with a spectrum of signs and symptoms of intractable epilepsy, developmental delay, ataxia, hearing loss, hypotonia,visual problems, alopecia and skin rash. Patients with later onset biotinidase deficiency may present with focal motor symptoms and visual problems. Deficient biotinidase enzyme activity $(<30 \%)$ in serum supports a diagnosis of biotinidase deficiency. The diagnosis is confirmed by sequence analysis of the BTD gene. Biotin supplementation in a dose ranging from 10 to $20 \mathrm{mg} / \mathrm{d}$ can improve the clinical picture, especially if started early. ${ }^{12}$ Recurrent subacute encephalopathy is one of the importance early features of biotin-thiamine-responsive basal ganglia disease. It is an increasingly recognized condition and can lead to coma and death if not promptly treated. Patients with biotin-thiamine-responsive basal ganglia disease may also have seizures, dystonia, and ophthalmoplegia, which may be provoked by a fever, minor stress, or surgery. Brain MRI is pathognomonic and shows $T_{2}$ increased signal intensity in the putamen, caudate, globi pallidi, thalami, brainstem, brain cortex, and cerebellum. Many reported cases were inherited as an autosomal recessive pattern due to $S L C 19 A 3$ pathogenic variants. ${ }^{13}$ Early treatment with biotin and thiamine can result in a dramatic clinical improvement. Biotin is given in dosage of $5-10 \mathrm{mg} / \mathrm{kg} / \mathrm{d}$ simultaneously with thiamine in dosage range from 300 to $900 \mathrm{mg} / \mathrm{d} .{ }^{13}$

Cerebral creatine deficiency syndromes described in the literature include L-arginine:glycine amidinotransferase deficiency, guanidinoacetate methyltransferase (GAMT) deficiency, and creatine transporter deficiency. The presentation of cerebral creatine deficiency syndromes usually includes seizures, intellectual delay, autistic features, speech delay, and movement disorders. Pathogenic variants of GAMT, GATM, and SLC6A8 are diagnostic. Cerebral 
Table 1 - Treatable vitamin-responsive epilepsy.

\begin{tabular}{|c|c|}
\hline Indication & Dose \\
\hline Pyridoxine (B6)-dependent epilepsy & $\begin{array}{c}\text { B6 } 15-30 \mathrm{mg} / \mathrm{kg} / \mathrm{d} \text { BID (up to } 500 \mathrm{mg} / \text { day) or }(50-100) \mathrm{mg} \text { IV with } \\
\text { simultaneous EEG recording. }\end{array}$ \\
\hline Pyridoxal 5'-phosphate-dependent epilepsy & Pyridoxal 5'-phosphate (30-50 mg/kg TID) \\
\hline Folinic acid-responsive seizures & Folinic acid $(3-5 \mathrm{mg} / \mathrm{kg} /$ dose $)$ \\
\hline Biotinidase deficiency & Biotin $(10-20 \mathrm{mg} /$ day $)$ \\
\hline Biotin-thiamine-responsive basal ganglia disease & Biotin $(5-10 \mathrm{mg} / \mathrm{kg} /$ dose $)$ and thiamine $(300-900 \mathrm{mg} /$ day $)$ \\
\hline Cerebral creatine deficiency syndromes & $\begin{array}{c}\text { GAMT deficiency: } \\
\text { Oral creatine monohydrate (dosage of } 400-800 \mathrm{mg} / \mathrm{kg} / \mathrm{day} \text { TID or more) } \\
\text { Ornithine }: 100 \mathrm{mg} / \mathrm{kg} / \mathrm{day} \\
\text { AGAT deficiency: } \\
\text { Oral creatine monohydrate (dosage of } 400-800 \mathrm{mg} / \mathrm{kg} / \text { day TID or more) } \\
\text { CRTR deficiency: } \\
\text { Creatine monohydrate } 100-200 \mathrm{mg} / \mathrm{kg} / \text { day TID } \\
\text { Arginine } 400 \mathrm{mg} / \mathrm{kg} / \mathrm{day} \text { TID } \\
\text { Glycine } 150 \mathrm{mg} / \mathrm{kg} / \text { day TID }\end{array}$ \\
\hline
\end{tabular}

GAMT - guanidinoacetate methyltransferase, AGAT - L-arginine:glycine amidinotransferase deficiency, CRTR - creatine transporter deficiency

Table 2 - Mitochondrial cocktail supplements

\begin{tabular}{|c|c|}
\hline Medication & Dose \\
\hline Riboflavin (B2) & $50-400 \mathrm{mg}$ po OD in children and $50-400 \mathrm{mg}$ po OD in adults \\
\hline Ubiquinone (coenzyme Q10) & $2-8 \mathrm{mg} / \mathrm{kg}$ po daily BID in children and $50-600 \mathrm{mg}$ po OD in adults \\
\hline L-Creatine & $\begin{array}{l}0.1 \mathrm{~g} / \mathrm{kg} \text { po OD; maximum } 10 \mathrm{~g} / \mathrm{d} \text { in children and } 5 \mathrm{~g} \text { po OD or BID } \\
\text { in adults }\end{array}$ \\
\hline L-Arginine & $150-300 \mathrm{mg} / \mathrm{kg}$ po BID to TID in children and adults \\
\hline L-Carnitine & $\begin{array}{l}10-100 \mathrm{mg} / \mathrm{kg} \text { daily po TID in children and } 100-1000 \mathrm{mg} \text { per dose po } \\
\text { BID to TID in adults }\end{array}$ \\
\hline Vitamin E & $1-2 \mathrm{IU} / \mathrm{kg}$ po daily in children and $100-200 \mathrm{IU}$ po daily in adults \\
\hline Vitamin C & $5 \mathrm{mg} / \mathrm{kg}$ po daily in children and $50-200 \mathrm{mg}$ po daily in adults \\
\hline Alpha-lipoic acid & $50-200 \mathrm{mg}$ per day \\
\hline
\end{tabular}

creatine pool is almost completely depleted on brain MR spectroscopy in males and females with GAMT deficiency and L-arginine:glycine amidinotransferase deficiency and in males with creatine transporter deficiency. Treatment with oral creatine monohydrate (dosage of $100-200 \mathrm{mg} / \mathrm{kg}$ in 3 doses) and a special diet can result in improvements in seizures and intellectual improvements (Table 1)..$^{14,15}$

In GLUT-1 deficiency, SLC2A1 gene mutations lead to a defect in glucose transport to brain cells and low CSF glucose. The clinical spectrum of GLUT-1 deficiency ranges from movement disorders to developmental delay, microcephaly and intractable epilepsy. A CSF glucose to serum glucose ratio of $<0.4$ supports a diagnosis of GLUT-1 deficiency. A ketogenic diet is the gold standard of care in patients with GLUT-1 deficiency. ${ }^{16}$

Some mitochondrial disorders can be associated with epilepsy. Mitochondrial myopathy, encephalopathy, lactic acidosis, and stroke-like episodes (MELAS), and myoclonic epilepsy with ragged red fibers (MERRF) are examples of progressive myoclonic epilepsies. A high serum, CSF, and magnetic resonance spectroscopy (MRS) lactate level, along with a muscle biopsy, may provide early clues of mitochondrial disorders. ${ }^{17}$ Oral administration of riboflavin (dose: $50-400 \mathrm{mg}$ po daily in children and $50-400 \mathrm{mg}$ po daily in adults) or ubiquinone (coenzyme Q10) (dose: $2-8 \mathrm{mg} / \mathrm{kg}$ po twice per day in children and 50-600 mg po given daily in adults) can yield improvements in some cases. Trials of cocktails of other mitochondrial supplements can also be considered (e.g., -L-creatine, L-arginine, L-carnitine, vitamin $\mathrm{E}$, vitamin $\mathrm{C}$, and $\alpha$-lipoic) (Table 2). ${ }^{18}$

Clinical presentation of urea cycle disorders can occur early in the neonatal period with encephalopathy, hypothermia, cerebral edema, and seizures. Late presentation can be episodic encephalopathy, seizures, vomiting, and ataxia. ${ }^{19}$ Accumulation of ammonia 
Table 3 - Review of Non-pharmacological options.

\begin{tabular}{|c|c|c|}
\hline Conditions & Treatments & Dose/notes \\
\hline Neuronal ceroid-lipofuscinoses type II & Cerliponase alfa & $\begin{array}{c}3 \text { years or older: } 300 \mathrm{mg} \text { by intraventricular infusion } \\
\text { once every other week }\end{array}$ \\
\hline Menkes disease & Copper histidine or copper chloride & $\begin{array}{c}\text { Cooper histidine subcutaneous: } \\
\text { Day } 1: 50 \mu \mathrm{g} / \mathrm{d} \\
\text { Day } 2: 100 \mu \mathrm{g} / \mathrm{d} \\
\text { Day } 3 \text { onward: } 150 \mu \mathrm{g} / \mathrm{d} \\
\text { Copper chloride subcutaneous: } \\
\text { Age }<1 \text { year: } 250 \mu \mathrm{g} 2 \mathrm{x} / \text { day } \\
\text { Age }>1 \text { year: } 250 \mu \mathrm{g} 1 \mathrm{x} / \text { day }\end{array}$ \\
\hline Tuberous sclerosis complex & Everolimus & $5 \mathrm{mg} / \mathrm{m}^{2} \mathrm{PO} \mathrm{qd}$ \\
\hline \multirow{2}{*}{$\begin{array}{l}\text { Epileptic encephalopathies like CSWS, LKS, } \\
\text { Doose, Rassmusen.. etc }\end{array}$} & Intravenous immunoglobulins & 1 - or 5 -day course of $2 \mathrm{~g} / \mathrm{kg}$ intravenous \\
\hline & Steroids & $\begin{array}{l}\text { Oral prednisolone (up to } 5 \mathrm{mg} / \mathrm{kg} / \mathrm{d} \text { ) over } 2-4 \text { weeks. } \\
\text { Methylprednisolone IV: } 20-30 \mathrm{mg} / \mathrm{kg} / \mathrm{d} \text { for } 3-5 \text { days }\end{array}$ \\
\hline $\begin{array}{l}\text { Epileptic encephalopathies like Dravet } \\
\text { syndrome and Lennox-Gastaut syndrome }\end{array}$ & Cannabidiol & $5-25 \mathrm{mg} / \mathrm{kg} / \mathrm{d}$ oral QD \\
\hline Dravet syndrome & Fenfluramine & 10 to $20 \mathrm{mg}$ daily \\
\hline Catamenial epilepsy, CSWS, LKS & Acetazolamide & 10 to $15 \mathrm{mg} / \mathrm{kg} / \mathrm{d}$ divided BID \\
\hline Focal lesion like DNET, FCD, glioma & Focal lesionectomy, lobectomy or laser ablation & \\
\hline Mesial temporal sclerosis & Temporal lobectomy & \\
\hline $\begin{array}{l}\text { Hemimegalencephaly or extensive unilateral } \\
\text { cortical dysplasia, Rasmussen encephalitis, } \\
\text { Sturge-Weber syndrome }\end{array}$ & Hemispherectomy & \\
\hline Lennox Gastatut syndrome & Corpus callosotomy & \\
\hline LKS & Multiple subpial transections & \\
\hline
\end{tabular}

and other precursor metabolites attributed to specific enzyme deficiency in the urea cycle. High ammonia, absence of metabolic acidosis or ketosis, and abnormal plasma levels of amino acids suggest a diagnosis of urea cycle disorders. The diagnosis is confirmed by molecular genetic testing and abnormal enzyme activity. Treatments for urea cycle disorders include dialysis in cases of hyperammonemic coma, catabolism reversal by glucose infusion and an insulin drip, and arginine and pharmacological scavenging of excess nitrogen..$^{20,21}$

Glutaric aciduria occurs due to increased glutaric acid urinary excretion. It is usually inherited as an autosomal recessive manner. This leads to 3-hydroxyglutaric and glutaric acid accumulation. Glutaryl-CoA dehydrogenase gene heterogeneous mutations have been described. ${ }^{22}$ Clinically, glutaric aciduria can present with acute decompensation after a febrile illness or dehydration. Later, macrocephaly, dystonia, and seizures may be observed. In chronic cases, brain MRI shows basal ganglia hyperintensities, cyst-like dilatation of Sylvian fissures, and brain atrophy. The addition of riboflavin (dose: $200 \mathrm{mg} / \mathrm{d}$ ) and L-carnitine (dose: 100 $\mathrm{mg} / \mathrm{kg} / \mathrm{d}$ ) to antiepileptic medications can result in a significant clinical improvement. ${ }^{23}$
Molybdenum cofactor deficiency is a severe epileptic encephalopathy. It is an inherited condition that usually occurs early in the neonatal period. It is similar to isolated sulfite oxidase deficiency, with the presence of intractable seizures, feeding difficulties, progressive severe intellectual disability, and spasticity. ${ }^{24}$

Molybdenum cofactor deficiency investigations show low serum uric acid levels and high urinary xanthine and hypoxanthine levels due to loss of function of xanthine dehydrogenase. Isolated sulfite oxidase deficiency is associated with positive urine sulfite on dipstick screening, elevated urinary thiosulfate and S-sulfocysteine, low urinary organic sulfate, normal serum uric acid levels, and low plasma total homocysteine. Molybdenum cofactor deficiency is caused by MOCS1, MOCS2, and GPHN mutations. On the other hand, isolated sulfite oxidase deficiency is caused by pathogenic variants in the SUOX gene. ${ }^{24}$ Intravenous administration of 80 to $160 \mu \mathrm{g}$ of purified cyclic pyranopterin monophosphate $/ \mathrm{kg}$ of body weight can improve seizures in molybdenum cofactor deficiency. ${ }^{25,26} \mathrm{~A}$ low-protein diet restricted in cysteine and methionine, betaine, thiamine, cysteamine, and penicillamine (chelating agents used to chelate sulfite) 
can be used to manage cases of isolated sulfite oxidase deficiency and alleviate seizures with no much benefit.

Tetrahydrobiopetrine (BH4) deficiency is a rare metabolic disease, which is responsible for $2 \%$ of hyperphenylalaninemia cases. Typically, infants with (BH4) deficienc are hypotonic and exhibit erratic myoclonus and oculogyric seizures, as well as progressive neurological deterioration, "also named malignant hyperphenylalaninemia”. Hyperphenylalaninemia, abnormalities in pterin metabolites in urine, dihydropteridine reductase in serum, CSF pterins, and neurotransmitters and reduced enzyme activity (red blood cells or fibroblasts) support a diagnosis of BH4 deficiency. Early treatment with a phenylalaninerestricted diet, BH4 $(5 \alpha 10 \mathrm{mg} / \mathrm{kg} / \mathrm{d})$, L-dopa, and 5-hydroxytryptophan can lead to improved outcomes. ${ }^{27}$

Enzyme replacement therapy and novel therapies. Some neurometabolic conditions can improve with appropriate enzyme replacement therapy. Neuronal ceroid-lipofuscinoses (NCLs) are a spectrum of conditions characterized by gradual motor and cognitive deterioration, poor vision, seizures, and early death. Epilepsy in such conditions can be intractable to most conventional AEDs. Electron microscopy of tissue biopsies may show curvilinear profiles, fingerprint profiles, or mixed inclusions. In addition, lysosomal enzyme levels may help in the diagnosis. Multiple pathogenic gene mutations have been reported in the literature in different NCL types using whole exome sequencing. Injection therapy with cerliponase alfa, a lysosomal N-terminal tripeptidyl peptidase, appears to slow the progression in symptomatic pediatric patients with late-infantile NCL type 2 (CLN2), which is caused by tripeptidyl peptidase1 deficiency. ${ }^{28}$ Replicationdeficient adeno-associated virus vector administration in CLN6 and immunosuppressant mycophenolate (mycophenolate mofetil) in CLN3 may halt disease and symptom progression. ${ }^{29,30}$

Menkes disease can present in early infancy, with regression of milestones, epilepsy, hypotonia, and failure to thrive. Infants with Menkes disease may also exhibit abnormal hair morphology, vascular tortuosity, and hypoglycemia. Many patients with Menkes disease die before the age of 3 y. Low serum copper and low ceruloplasmin concentrations are initial clues to the diagnosis. ATP7A pathogenic mutations affecting copper transport have been reported. ${ }^{31}$ Subcutaneous injections of copper histidine or copper chloride before the age of $10 \mathrm{~d}$ can normalize developmental and neurological outcomes. ${ }^{32}$

Tuberous sclerosis complex (TSC) is a multisystemic condition affecting the brain, skin, kidneys, heart, liver, lungs, and eyes. It is characterized by a spectrum of signs and symptoms attributed to mutations affecting the proteins hamartin and tuberin. Epilepsy is a major burden of TSC. It can affect $80-90 \%$ of TSC patients. ${ }^{33}$ Many TSC patients remain intractable to standard AEDs. Mammalian target of rapamycin (mTOR) inhibitors are novel therapies for TSC. The FDA approved everolimus (an mTOR inhibitor) in April 2018 for TSC-associated partial-onset seizures for pediatric and adult patients aged $2 \mathrm{y}$ and older. Multiple mechanisms explain mTOR efficacy in TSC. These include glucose regulation and effects on epilepsy signaling, cell growth, cell proliferation, and cell survival. In $40 \%$ of patients with TSC, mTOR improve seizures. The initial dose of everolimus is usually $5 \mathrm{mg} / \mathrm{m}^{2} \mathrm{PO} \mathrm{qd}$. Adverse events may include stomatitis, infections, diarrhea, a rash, and abnormal liver function. ${ }^{34}$

Some certain conditions might get benefit of specific medications "precision medicine" like Dravet syndrome due to SCN1A mutations. Recently, fenfluramine which is a serotonergic medication used for appetite suppression found to have potential benefits in Dravet patients. Seizure improvement was more than 90\% after adding fenfluramine to their AEDs. ${ }^{35}$ Average total doses were 10 to $20 \mathrm{mg}$ daily. Anorexia and behavioral changes were noticed in few patients.

GRIN2A-related epilepsy can present with intellectual delay and evolve into intractable epilepsy. Memantine is an investigational medication with potential future benefits in GRIN2A-epilepsy. It works by NMDA channel modulation. ${ }^{36}$ Another geneticprecision medication with ongoing research on its effectiveness in KCNT1-related epilepsy like epilepsy of infancy with migrating focal seizures is quinidine. Quinidine is antiarrhythmic medication. It acts on neurons and cardiomyocytes potassium channels. ${ }^{37}$

Ketogenic diet. A ketogenic diet is a high-fat, adequate-protein, low-carbohydrate diet that has been used to treat intractable epilepsy since the early 1900 s. It acts by altering brain energy substrates and cerebral acidosis and directly affecting ketones in the brain. ${ }^{38} \mathrm{~A}$ ketogenic diet is indicated as first-line therapy in glucose transporter deficiency syndrome. It is also indicated in cases of medication failure in many conditions, for example, pyruvate dehydrogenase complex deficiency, severe myoclonic epilepsy of infancy (Dravet syndrome), myoclonic-astatic epilepsy (Doose syndrome), infantile spasms, acquired epileptic aphasia (Landau-Kleffner syndrome), tuberous sclerosis complex and Rett syndrome. A ketogenic diet is contraindicated in children with severe gastroesophageal reflux or poor weight gain. Patients with some conditions are not candidates for 
a ketogenic diet. These include patients with pyruvate carboxylase deficiency, porphyria, defects in fatty acid oxidation, and carnitine deficiency. ${ }^{39}$ A ketogenic diet can be initiated in an in-patient or out-patient setting. Basic blood investigations are usually performed before diet commencement. A gradual increment in the fat ratio $(3: 1$ or $4: 1)$ is usually implemented over a 3-day to 1 -week period. The efficacy of a ketogenic diet varies according to different studies and conditions. ${ }^{36}$ More than $50 \%$ of children treated with ketogenic diet may achieve more than $50 \%$ decrease in their epilepsy. Side effects of this type of diet include hypoglycemia, dehydration, vomiting, renal stones, and mineral deficiencies. ${ }^{39}$

Inflammatory mediators. Neuroinflammation may be a contributing factor to many epilepsy syndromes with different etiologies. ${ }^{40}$ Intravenous immunoglobulins (IVIgs) and steroids have been used off-label in epilepsy, with variable outcomes. In $24-84 \%$ of cases, children with epilepsy with different etiologies improved after either steroid or IVIg treatment. ${ }^{41}$ Inflammatory mediators are recommended for some epilepsy syndromes, such as Landau-Kleffner syndrome, Rasmussen's encephalitis, and Doose syndrome, as well as for cases of continuous spikes and waves during sleep and infantile spasms. There is strong evidence in the literature for the efficacy of IVIg and steroids as treatments for various disorders, such as Lennox-Gastaut syndrome, gelastic seizures, idiopathic epilepsy, and status epilepticus. In terms of the treatment dose, IVIgs are usually given in a divided dosage twice per day in a 1 - or 5 -d course of $2 \mathrm{~g} / \mathrm{kg}$. The efficacy can be observed in a week up to 6 mo. Side effects are rare, but they include flushing, myalgia, chills, tachycardia, lower back pain, hypotension, aseptic meningitis, headaches, and hyperviscosity. ${ }^{42}$ Corticosteroids (prednisone, prednisolone, adrenocorticotrophin hormone, hydrocortisone, and methylprednisolone) are administered in variable dosage and formulations. For example, infantile spasms may be treated with oral prednisolone (up to $5 \mathrm{mg} / \mathrm{kg} / \mathrm{d}$ ) over 2-4 weeks. Methylprednisolone IV pulse therapy is an additional treatment option, with a dose of $20-30 \mathrm{mg} / \mathrm{kg} / \mathrm{d}$ usually given over 3-5 days, followed by an oral weaning course. Efficacy may be observed within a few days to up to 2 weeks. Possible side effects of steroids are hypertension, weight gain, hyperglycemia, acne, blurred vision, easy bruising, cataracts, glaucoma, and hirsutism. ${ }^{42}$

Cannabinoids. Cannabis-based therapies, such as cannabidiol (CBD), have captured attention recently as an add-on treatment for intractable epilepsy, with many randomized controlled trials supporting its efficacy. CBD decreased the seizure frequency in cases of intractable epilepsy, especially among patients with epileptic encephalopathies (e.g., Dravet syndrome and Lennox-Gastaut syndrome). ${ }^{43}$ In addition, CBD was superior to other AEDs in terms of side effects, although it caused somnolence and dizziness initially in some cases. Minimal drug interactions have been reported with CBD. It can increase the levels of clobazam. ${ }^{44} \mathrm{In}$ terms of the dosage, CBD treatment commences with a dose of $2-5 \mathrm{mg} / \mathrm{kg} / \mathrm{d}$ twice daily and is then increased to a maximum dose of $25 \mathrm{mg} / \mathrm{kg}$. Seizures improved in 39\% of patients taking Epidiolex, an FDA-approved form of CBD. ${ }^{45}$

Some other herbal remedies have potential antiepileptogenic characteristics. The literature is scare regarding randomized controlled trials of herbal extracts. However, few case reports in literature mentioned variable responses in seizures frequency for patients used for example ginseng, ficus platyphylla, ganoderma lucidum and others. ${ }^{46,47}$

Other medications: diuretics. Acetazolamide is a carbonic anhydrase inhibitor. It can be used in multiple medical conditions, including glaucoma, hypokalemic periodic paralysis, motion sickness, increased intracranial hypertension, and epilepsy. Some expert opinions support the use of acetazolamide in epilepsy. For example, catamenial epilepsy can be treated with acetazolamide. ${ }^{48}$ Some case reports pointed to benefits of acetazolamide in Landau-Kleffner syndrome and continuous spikes and waves in slow-wave sleep. ${ }^{49}$ Acetazolamide in doses ranging from 10 to $15 \mathrm{mg} /$ $\mathrm{kg} / \mathrm{d}$ divided BID improved seizures in patients with intractable epilepsy. Side effects include perioral tingling, GI upset, polyuria, hypokalemia, and renal stones.

Epilepsy surgeries. Focal lesionectomy, lobectomy, multilobar resection, hemispherectomy, corpus callosotomy, and multiple subpial transection are some surgical options for children with intractable epilepsy who are candidates for epilepsy surgery. ${ }^{50}$ Temporal lobectomy is one of the most common epilepsy surgery types performed in adults and adolescents. In epilepsy patients with mesial temporal sclerosis, there is up to a $90 \%$ chance of rendering them free of seizures. ${ }^{51}$ Focal lesionectomy can result in a $60 \%$ chance of seizure freedom. ${ }^{52}$ Extratemporal cortical resection is more commonly performed in children. Focal cortical dysplasias are a common cause of intractable epilepsy in children. A hemispherectomy is indicated in intractable epilepsy cases limited to one hemisphere. These include Rasmussen encephalitis, hemimegalencephaly, Sturge-Weber syndrome, and congenital porencephaly postinfarction. Up to $80 \%$ of patients may be seizure free posthemispherectomy. ${ }^{53}$ 
Multiple subpial transection may be a palliative option in cases of Landau-Kleffner syndrome. In such patients, the epileptogenic zone situated over eloquent cortex. Multiple subpial transection leads to disruption of the network of horizontal fibers, with variable outcomes. Corpus callosotomy is another palliative surgery indicated in intractable epilepsy with tonic and atonic seizures, such as those observed in Lennox-Gastaut syndrome. Some epilepsy surgeries may result in postsurgical complications, including bleeding, stroke, infection, and loss or disturbance of eloquent area function, depending on its location, type of surgery, use of intraoperative recording, and age of the patient. (Table 3)

Neurostimulation. Neuromodulation or neurostimulation is defined as "alteration of nerve activity through targeted delivery of a stimulus, such as chemical agents or electrical stimulation, to specific neurological sites in the body" ${ }^{54}$ It is one of the available techniques to control epilepsy in pharmacoresistant patients. Unlike AEDs, neuromodulation does not cause hepatotoxicity, nephrotoxicity, or blood dyscrasias. Neurostimulation may improve seizures by more than $50 \%$ in some patients. ${ }^{55}$ On the other hand, most neuromodulation modalities are expensive. However, a previous study demonstrated that neurostimulation was effective in terms of health system costs. ${ }^{56}$

One of the most common and well-known neuromodulation protocols is vagus nerve stimulation (VNS). It is indicated as adjunctive therapy for medically refractory epilepsy, and it has also been used to treat depression. In VNS, a VNS device is usually implanted below the skin of the upper chest and connected to the left vagus nerve. There are different theories underlying how VNS controls epilepsy. According to one theory, stimulation of the thalamus via the medial reticular formation modifies the seizure threshold. Another theory posits that a reduction in medial thalamus metabolic activity by VNS leads to better seizure control. It works by intermittent, fixed vagus nerve stimulation as an open-loop system. VNS with heart rhythm detection tool for better seizures detection has become available also. It is a closed-loop system that detects heart rate and respond accordingly. ${ }^{57}$ The VNS can lead to more than a $50 \%$ reduction in seizure burden. Recently, Transcutaneous VNS has been developed as a less invasive method than traditional VNS. It is done without surgical implantation and reaches the vagus nerve via its auricular branch. ${ }^{58}$ VNS-related side effects are usually minor and include temporary hoarseness, cough, swallowing difficulties, or local infection..$^{59}$
Responsive neurostimulation is another novel treatment paradigm for epilepsy. It is indicated as adjunctive therapy of medically intractable focal onset seizures in adults, with localized one or 2 epileptogenic foci. Patients with lesions involving the eloquent cortex may benefit from this treatment protocol. This closed-loop system works by recording and responding to seizures by direct stimulation. Responsive neurostimulation can lead to a $38 \%$ decrease in seizure frequency. ${ }^{60}$

Deep brain stimulation is currently approved as a treatment modality for movement disorders. Stimulation targeting the anterior nucleus of the thalamus can decrease seizure frequency. Impulses travel through the anterior nucleus of the thalamus and via projections to the hypothalamus and fibers to the hippocampus, amygdala, hypothalamus and orbito-frontal cortex. Deep brain stimulation is similar to VNS. A generator is implanted below the skin in the chest, and two intracranial electrodes are placed stereotaxically. Like VNS, few complications are reported with deep brain stimulation. In the SANTE trial, patients achieved a $43 \%$ reduction in seizure frequency. ${ }^{61}$

Repetitive transcranial magnetic stimulation (rTMS) involves focal noninvasive brain stimulation using a hand-held electromagnet. Low frequency (0.3-1 $\mathrm{Hz})$ rTMS can have antiseizure therapeutic effect by inducing a lasting reduction in cortical excitability. Multiple rTMS studies reported positive results in terms of reducing epileptiform discharges. However, rTMS is still clinically limited as it requires frequent hospital visits, it has variable techniques and the evidence for its efficacy on seizure reduction is controversial. ${ }^{62}$ Adverse effects like in-session seizures, headache, tinnitus and facial twitches have been reported. ${ }^{63}$

Laser interstitial thermal therapy. Laser interstitial thermal therapy (LITT) or stereotactic laser ablation is one of a rapidly growing number of minimally invasive surgical techniques. The treatment is administered by MRI-guided thermal laser ablation, which causes tissue coagulation. A major advantage of laser interstitial thermal therapy is minimal postsurgical complications as compared with those using open surgical approaches and hence shorter hospital stays. It can be used in epilepsy cases caused by hypothalamic hamartomas, focal cortical dysplasia, mesial temporal sclerosis, tuberous sclerosis, and focal migrational anomalies. A $75 \%$ seizure-freedom after LITT for hypothalamic hamartomas was reported. Though the seizure-free outcomes after LITT for temporal lobe epilepsy is still inferior to the gold standard surgical approach, it has a promising future directive and less collateral damage. Targeted tubers ablation in children with TSC can 
result in $70 \%$ decrease in their seizure burden. ${ }^{64}$ Side effects of laser interstitial thermal therapy occur in less than $10 \%$ of cases and include focal cranial nerve palsies, hemorrhages, or hydrocephalus. ${ }^{65}$

Conclusion. Novel therapies to treat epilepsy are emerging. Seizures in many patients diagnosed with intractable epilepsy may improve or even disappear with proper management. Reducing the seizure burden will have positive impacts on quality of life, including social well-being, as well as morbidity and survival. Although there are many options to treat epilepsy, unfortunately, many cases remain intractable. Hopefully, future studies shedding light on new epilepsy treatment regiments will lead toward better control on intractable epilepsy.

Acknowledgement. The author would like to thank Scribendi company (https://www.scribendi.com) for English language editing.

\section{References}

1. Fiest KM, Sauro KM, Wiebe S, Patten SB, Kwon CS, Dykeman J, et al. Prevalence and incidence of epilepsy: A systematic review and meta-analysis of international studies. Neurology 2017; 88: 296-303.

2. Al Rajeh S, Awada A, Bademosi O, Ogunniyi A. The prevalence of epilepsy and other seizure disorders in an Arab population: a community-based study. Seizure 2001; 10: 410-414.

3. Brodie MJ. Seizure. Antiepileptic drug therapy the story so far. Seizure 2010; 19: 650-655

4. Sinha S, Siddiqui KA. Definition of intractable epilepsy. Neurosciences (Riyadh) 2011; 16: 3-9.

5. Gospe SM Jr. Neonatal vitamin-responsive epileptic encephalopathies. Chang Gung Med J 2010; 33: 1-12.

6. Tabarki B, Thabet F. Vitamin-responsive epilepsies: an update. Arch Pediatr 2013; 20: 1236-1241.

7. Coughlin CR 2nd, Swanson MA, Spector E, Meeks NJL, Kronquist KE, Aslamy M, et al. The genotypic spectrum of ALDH7A1 mutations resulting in pyridoxine dependent epilepsy: A common epileptic encephalopathy. J Inherit Metab Dis 2019; 42: 353-361.

8. Falsaperla R, Corsello G. Pyridoxine dependent epilepsies: new therapeutical point of view. Ital J Pediatr 2017; 43: 68.

9. Xue J, Chang X, Zhang Y, Yang Z. Novel phenotypes of pyridox(am)ine-5'-phosphate oxidase deficiency and high prevalence of c.445_448del mutation in Chinese patients. Metab Brain Dis 2017; 32: 1081-1087

10. Gallagher RC, Van Hove JL, Scharer G, Hyland K, Plecko B, Waters PJ, et al. Folinic acid-responsive seizures are identical to pyridoxine-dependent epilepsy. Ann Neurol 2009; 65: 550-556.

11. Al-Baradie RS, Chaudhary MW. Diagnosis and management of cerebral folate deficiency: A form of folinic acid-responsive seizures. Neurosciences (Riyadh) 2014; 19: 312-316.

12. Canda E, Yazici H, Er E, Kose M, Basol G, Onay H, et al. Single center experience of biotinidase deficiency: 259 patients and six novel mutations. J Pediatr Endocrinol Metab 2018; 31 : 917-926
13. Alfadhel M, Almuntashri M, Jadah RH, Bashiri FA, Al Rifai MT, Al Shalaan H, et al. Biotin-responsive basal ganglia disease should be renamed biotin-thiamine-responsive basal ganglia disease: a retrospective review of the clinical, radiological and molecular findings of 18 new cases. Orphanet J Rare Dis 2013; 8: 83 .

14. Mørkrid L, Rowe AD, Elgstoen KB, Olesen JH, Ruijter G, Hall $\mathrm{PL}$, et al. Continuous age- and sex-adjusted reference intervals of urinary markers for cerebral creatine deficiency syndromes: a novel approach to the definition of reference intervals. Clin Chem 2015; 61: 760-768.

15. Rostami P, Hosseinpour S, Ashrafi MR, Alizadeh H, Garshasbi M, Tavasoli AR. Primary creatine deficiency syndrome as a potential missed diagnosis in children with psychomotor delay and seizure: case presentation with two novel variants and literature review. Acta Neurol Belg 2019; 20.

16. Daci A, Bozalija A, Jashari F, Krasniqi S. Individualizing Treatment Approaches for Epileptic Patients with Glucose Transporter Type1 (GLUT-1) Deficiency. Int J Mol Sci 2018; 19: 122.

17. Murayama K, Shimura M, Liu Z, Okazaki Y, Ohtake A. Recent topics: the diagnosis, molecular genesis, and treatment of mitochondrial diseases. J Hum Genet 2019; 64; 113-125.

18. Hirano M, Emmanuele V, Quinzii CM. Emerging therapies for mitochondrial diseases. Essays Biochem 2018; 62: 467-481.

19. Summar ML, Ah Mew N. Inborn errors of metabolism with hyperammonemia: urea cycle defects and related disorders. Pediatric Clinics of North America 2018; 65: 231-246.

20. Matsumoto S, Häberle J, Kido J, Mitsubuchi H, Endo F, Nakamura K. Urea cycle disorders-update. J Hum Genet 2019; 64: 833-847.

21. Soria LR, Ah Mew N, Brunetti-Pierri N. Progress and challenges in development of new therapies for urea cycle disorders. Hum Mol Genet 2019; 28: R42-R48.

22. Zayed H, El Khayat H, Tomoum H, Khalifa O, Siddiq E, Mohammad SA, et al. Clinical, biochemical, neuroradiological and molecular characterization of Egyptian patients with glutaric acidemia type 1. Metab Brain Dis 2019; 34: 1231-1241.

23. Boy N, Mühlhausen C, Maier EM, Heringer J, Assmann B, Burgard P. et al. Proposed recommendations for diagnosing and managing individuals with glutaric aciduria type I: second revision. J Inherit Metab Dis 2017; 40: 75-101.

24. Mechler K, Mountford WK, Hoffmann GF, Ries M. Ultraorphan diseases: a quantitative analysis of the natural history of molybdenum cofactor deficiency. Genet Med 2015; 17: 965-970.

25. Scelsa B, Gasperini S, Righini A, Iascone M, Brazzoduro VG, Veggiotti P. Mild phenotype in Molybdenum cofactor deficiency: A new patient and review of the literature. $\mathrm{Mol}$ Genet Genomic Med 2019; 7: e657.

26. Edwards M, Roeper J, Allgood C, Chin R, Santamaria J, Wong $\mathrm{F}$, et al Investigation of molybdenum cofactor deficiency due to MOCS2 deficiency in a newborn baby. Meta Gene 2015; 31; 3: $43-49$.

27. Longo N. Disorders of biopterin metabolism. J Inherit Metab Dis 2009; 32: 333-342.

28. Schulz A, Ajayi T, Specchio N, de Los Reyes E, Gissen P, Ballon $\mathrm{D}$, et al. Study of intraventricular cerliponase alfa for CLN2 disease. N Engl J Med 2018; 378: 1898-1907.

29. Griffey M, Bible E, Vogler C, Levy B, Gupta P, Cooper J, et al. Adeno-associated virus 2-mediated gene therapy decreases autofluorescent storage material and increases brain mass in a murine model of infantile neuronal ceroid lipofuscinosis. Neurobiol Dis 2004; 16: 360-369. 
30. Augustine EF, Beck CA, Adams HR, Defendorf S, Vierhile A, Timm D, et al. Short-Term Administration of Mycophenolate Is Well-Tolerated in CLN3 Disease (Juvenile Neuronal Ceroid Lipofuscinosis). JIMD Rep 2019; 43: 117-124.

31. Skjørringe T, Pedersen PA, Thorborg SS, Nissen P, Gourdon P, Møller LB. Characterization of ATP7A missense mutants suggests a correlation between intracellular trafficking and severity of Menkes disease. Sci Rep 2017; 7: 757.

32. Ogata R, Chong PF, Maeda K, Imagi T, Nakamura R, Kawamura N, et al. Long surviving classical Menkes disease treated with weekly intravenous copper therapy. J Trace Elem Med Biol 2019; 54: 172-174.

33. Overwater IE, Bindels-de Heus K, Rietman AB, Ten Hoopen LW, Vergouwe Y, Moll HA, et al. Epilepsy in children with tuberous sclerosis complex: chance of remission and response to antiepileptic drugs. Epilepsia 2015; 56: 1239-1245.

34. French JA, Lawson JA, Yapici Z, Ikeda H, Polster T, Nabbout $\mathrm{R}$, et al. Adjunctive everolimus therapy for treatment-resistant focal-onset seizures associated with tuberous sclerosis (EXIST-3), a Phase III, randomised, double-blind, placebo-controlled study. Lancet 2016; 388: 2153-2163.

35. Ceulemans B, Schoonjans AS, Marchau F, Lagae L, Paelinck BP. Five-year extended follow-up status of 10 patients with Dravet syndrome treated with fenfluramine. Epilepsia 2016; 57: e129-e134.

36. Strehlow V, Heyne HO, Vlaskamp DRM, Marwick KFM, Rudolf G, de Bellescize J. et al. GRIN2A study group, GRIN2Arelated disorders: genotype and functional consequence predict phenotype. Brain 2019; 142; 80-92.

37. Mikati MA, Jiang YH, Carboni M, Shashi V, Petrovski S, Spillmann R, et al. Quinidine in the treatment of KCNT1positive epilepsies. Ann Neurol 2015; 78: 995-999.

38. Alberti MJ, Agustinho A, Argumedo L, Armeno M, Blanco $\mathrm{V}$, Bouquet C, et al. Recommendations for the clinical management of children with refractory epilepsy receiving the ketogenic diet. Arch Argent Pediatr 2016; 114: 56-63.

39. Armeno M, Araujo C, Sotomontesano B, Caraballo RH. Update on the adverse effects during therapy with a ketogenic diet in paediatric refractory epilepsy. Rev Neurol 2018; 66: 193-200.

40. Tang-Wai R, Mailo J, Rosenblatt B. Breaking the cycle: A comparison between intravenous immunoglobulins and high dosage prednisone in the treatment of medically intractable epilepsy in children. Seizure 2017; 47: 34-41.

41. o-Espinosa LE, Rajapakse T, Rho JM, Buchhalter J. Efficacy of intravenous immunoglobulin in a cohort of children with drug-resistant epilepsy. Pediatr Neurol 2015; 52: 509-516.

42. Kurian M, Korff CM. Steroids in pediatric epilepsy: infantile spasms and beyond. Epileptologie 2011; 28: 15-20.

43. Stockings E, Zagic D, Campbell G, Weier M, Hall WD, Nielsen $S$, et al. Evidence for cannabis and cannabinoids for epilepsy: a systematic review of controlled and observational evidence. $J$ Neurol Neurosurg Psychiatry 2018; 89: 741-753.

44. Geffrey AL, Pollack SF, Bruno PL, Thiele EA. Drug-drug interaction between clobazam and cannabidiol in children with refractory epilepsy. Epilepsia 2015; 56: 1246-1251.

45. Campbell CT, Phillips MS, Manasco K. Cannabinoids in pediatrics. J Pediatr Pharmacol Ther 2017; 22: 176-185.

46. Liu W, Ge T, Pan Z, Leng Y, Lv J, Li B. The effects of herbal medicine on epilepsy. Oncotarget 2017; 8: 48385-48397.

47. Bahr TA, Rodriguez D, Beaumont C, Allred K. The effects of various essential oils on epilepsy and acute seizure: a systematic review. Evid Based Complement Alternat Med 2019; 22; 2019: 6216745
48. Lim LL, Foldvary N, Mascha E, Lee J. Acetazolamide in women with catamenial epilepsy. Epilepsia 2001; 42: 746-749.

49. Fine AL, Wirrell EC, Wong-Kisiel LC, Nickels KC. Acetazolamide for electrical status epilepticus in slow-wave sleep. Epilepsia 2015; 56: e134-e138.

50. West S, Nolan SJ, Newton R. Surgery for epilepsy: a systematic review of current evidence. Epileptic Disord 2016; 18: 113-121.

51. Lee AT, Burke JF, Chunduru P, Molinaro AM, Knowlton R, Chang EF. A historical cohort of temporal lobe surgery for medically refractory epilepsy: a systematic review and metaanalysis to guide future nonrandomized controlled trial studies. J Neurosurg 2019; 28: 1-8.

52. Yoon Ha Hwang, Na Young Jung, Chang Kyu Park, Won Seok Chang, Hyun Ho Jung, Jin Woo Chang. Factors Related to the Clinical Outcomes of Surgery for Extra-Temporal Lobe Epilepsy: Long-Term Follow-Up Results. World Neurosurg 2018; 115: e645-e649.

53. Bartoli A, El Hassani Y, Jenny B, Momjian S, Korff CM, Seeck $\mathrm{M}$, et al. What to do in failed hemispherotomy? Our clinical series and review of the literature. Neurosurg Rev 2018; 41: 125-113.

54. Eastin TM, Lopez-Gonzalez MA. Stimulation and Neuromodulation in the Treatment of Epilepsy. Brain Sci 2017; 8: 2 .

55. Jamy R, Kaur M, Pizarro D, Toth E, Pati S. Practice trends and the outcome of neuromodulation therapies in epilepsy: A single-center study. Epilepsia Open 2019; 4: 493-497.

56. Purser MF, Mladsi DM, Beckman A, Barion F, Forsey J. Expected budget impact and health outcomes of expanded use of vagus nerve stimulation therapy for drug-resistant epilepsy. Adv Ther 2018; 35: 1686-1696.

57. Hamilton P, Soryal I, Dhahri P, Wimalachandra W, Leat A, Hughes D, et al. Clinical outcomes of VNS therapy with AspireSR ${ }^{\oplus}$ (including cardiac-based seizure detection) at a large complex epilepsy and surgery centre. Seizure 2018; 58: 120-126.

58. Kong J, Fang J, Park J, Li S, Rong P. Treating depression with transcutaneous auricular vagus nerve stimulation: state of the art and future perspectives. Front Psychiatry 2018; 9: 20.

59. Johnson RL, Wilson CG. A review of vagus nerve stimulation as a therapeutic intervention. J Inflamm Res 2018; 11: 203-213.

60. Bergey GK, Morrell MJ, Mizrahi EM, Goldman A, KingStephens D, Nair D, et al. Long-term treatment with responsive brain stimulation in adults with refractory partial seizures. Neurology 2015; 84: 810-817.

61. Salanova V, Witt T, Worth R, Henry TR, Gross RE, Nazzaro JM, et al. Long-term efficacy and safety of thalamic stimulation for drug-resistant partial epilepsy. Neurology 2015; 84: 1017-1025.

62. Chen R, Spencer DC, Weston J, Nolan SJ. Transcranial magnetic stimulation for the treatment of epilepsy. Cochrane Database of Systematic Reviews 2016; 8: 1465-1858.

63. Shon YM, Lim SC, Lim SH. Therapeutic effect of repetitive transcranial magnetic stimulation on non-lesional focal refractory epilepsy. J Clin Neurosci 2019; 63: 130-133.

64. Grewal SS, Tatum WO. Laser thermal ablation in epilepsy. Expert Rev Neurother 2019: 12: 1211-1218.

65. Grewal SS, Alvi MA, Lu VM, Wahood W, Worrell GA, Tatum W, et al. Magnetic resonance-guided laser interstitial thermal therapy versus stereotactic radiosurgery for medically intractable temporal lobe epilepsy: a systematic review and meta-analysis of seizure outcomes and complications. World Neurosurg 2019; 122: e32-e47. 